\title{
Modelling Volume Change Potential in the London Clay
}

\author{
L. D. Jones \& R. Terrington
}

British Geological Survey, Keyworth, Nottingham. NG12 5GG UK (e-mail: ldjon@bgs.ac.uk)

\begin{abstract}
The London Clay Formation is particularly susceptible to shrink-swell behaviour that has resulted in a long history of foundation damage due to ground movement across the outcrop. Damage has cost up to $£ 500$ million in a single year. Underlying most of the Greater London area, the London Clay Formation is of major engineering importance as it is on and within this formation that the majority of the city's infrastructure, buildings and underground services are constructed. The Volume Change Potential of a soil is the relative change in volume to be expected with changes in soil moisture content and the subsequent shrinkage or swelling can cause major damage to structures above or below ground. Detailed statistical and spatial analyses of data across the London Clay outcrop has revealed a significant geographical trend in the volume change potential of this deposit, confirming an overall increase from west to east, but also showing subtle trends with depth. This paper describes how this analysis was carried out and shows how such assessments can yield valuable information about shrink-swell behaviour not only of the London Clay but of similar shrinkswell prone argillaceous formations elsewhere.
\end{abstract}

\section{Introduction}

The effects of shrinkage and swelling of clay soils, with respect to foundation and building damage, were first recognised by geotechnical specialists following the dry summer of 1947. After the drought of 1975-76 insurance claims in the UK came to over $£ 50$ million. In 1991, after a preceding drought, claims peaked at over $£ 500$ million. The Association of British Insurers has estimated that the average cost of shrink-swell related subsidence to the insurance industry stands at over $£ 400$ million a year. If the UK were to experience an increase in extended periods of dry weather, prior to future rainfall events, costs could rise significantly.

\section{London Clay - Geological Outline}

The London Clay Formation is of major importance in the fields of geotechnical engineering and engineering geology. This is because it has hosted a large proportion of sub-surface engineering works in London over the last 150 years. It has also been the subject of internationally recognised research in soil mechanics over the last 50 years (Skempton \& Delory, 1957; Chandler \& Apted, 1988 and Takahashi et al., 2005). The London Clay is subject to shrinkage and swelling behaviour, which has resulted in a long history of foundation damage within the outcrop. Although it has been the most commonly used soils testing material (assumed to have a uniform consistency throughout) since the early 1960s, few publications have covered the Volume Change Potential of the formation, except as a subsidiary topic in Burnett \& Fookes (1974) and Forster (1997) and, more recently, the geotechnical studies of Hight et al. (2002) and Pantelidou \& Simpson (2007). The term 'London Clay', used in this paper, refers to the dominantly clay lithologies within the London Clay Formation. 
The London Clay Formation outcrop, and subcrop, in southern England is confined to the London and Hampshire Basins. It has an extensive outcrop in the London Basin, due to the erosion of much of the overlying deposits. In the Hampshire Basin the outcrop is a narrow strip, less than $3 \mathrm{~km}$ in width. The total, onshore, sub-crop area of the London Clay Formation is approximately $6,400 \mathrm{~km}^{2}$ and the total outcrop is approximately $2,300 \mathrm{~km}^{2}$, about $1 \%$ of the area of Great Britain (based on the British Geological Survey 1:250k digital geology map DigMap 250k.

Typical unweathered London Clay is a firm to very stiff, fissured, dark grey or blue-grey silty clay deposited in a marine shelf environment in a tropical climate during the Eocene (Murray \& Wright, 1974 and Sellwood \& Sladen, 1981). The western part of the sequence is interpreted to have been deposited near to land and the eastern part in the deeper water of the North Sea Basin (Curry, 1992). When weathered, the London Clay is a soft to firm brown clay with ochreous staining due to oxidation of iron compounds. The clay itself may be pale grey or grey-green due to leaching (Smith, 1989). In the east of the London Basin Clay dominates the sequence with inter-bedded fine sand and silt; in the west it generally contains more sand and silt. In the Hampshire Basin the London Clay is generally more sandy and silty throughout.

\section{Thickness}

In the London Basin the total London Clay Formation thickness is between $90 \mathrm{~m}$ in the west thickening to $150 \mathrm{~m}$ in the east (Sellwood \& Sladen, 1981). In the Hampshire Basin the London Clay thickens from Alum Bay in the west $(75 \mathrm{~m})$ to Whitecliff Bay in the east $(142 \mathrm{~m})$. Much of the outcrop is covered by Quaternary deposits. Presently, the succession considered to be definitive is that described by King (1981), though the upper boundary is still disputed (Daley, 1999).

\section{Lithology}

The London Clay Formation varies in lithology, being dominantly argillaceous but containing layers with significant proportions of fine sand at the top and bottom of the sequence, and to the west. The basement beds of the London Clay Formation are characterised by glauconitic sandy silts whilst the uppermost beds comprise a flint pebble bed and sandy clayey silts with bands of sideritic ironstone nodules. Gypsum and selenite are found as individual crystals, or small clusters of crystals, formed by the oxidation of pyrite during weathering reacting with calcium carbonate released from shelly material (Lake et. al., 1986). Concretions of various kinds are found in the London Clay Formation; they include septarian nodules that form large spheroids (typically 30 to $50 \mathrm{~cm}$ in diameter) of cemented mudstone, containing ferroan calcite. Based on major revisions of the London Clay Formation carried out by King (1981), and later by Ellison et al. (1994 \& 2004), four informal lithostratigraphical units (Units A to D) and the formally named Claygate Member have now been recognised (Figure 1).

\section{Mineralogy}

The dominant clay mineral in the London Clay is illite. Subsidiary clay minerals are mixed layer clays (mainly smectite) and kaolinite (particularly in the west Hampshire basin and in Dorset). Discrete smectite horizons are common at the base of the London Clay Formation, in the central and eastern parts of the London Basin. Like similar deposits in the underlying Thanet Sand Formation these probably represent altered volcanic ash (Knox, 1979). Acidic groundwater results from the weathering of pyrite, which is widely dispersed throughout the London Clay Formation. Corrosion of iron tunnel linings has been attributed to pyrite oxidation within sand lenses at the base of the London Clay Formation (Rainey \& 
Rosenbaum, 1989) and acid groundwater attack has been reported at Old Street Station, London by Mather (1985) and is associated with rising groundwater levels (Chisholm, 1984). Crystals of gypsum and selenite are found throughout both fresh and weathered London Clay. Zeolites are found in association with smectite bands and traces of chlorite are also found within the London Clay Formation.

In the London area, the London Clay Formation is associated with rising groundwater levels as a consequence of diminished abstraction from the underlying Chalk aquifer. This has implications for both increasing the flooding hazard, in water sources and in to basement areas, and problems for engineering development including swelling associated with existing foundations (Lerner \& Barrett, 1996 and Simpson et al., 1989).

Figure 1 - Lithostratigraphical sequence of the London Clay Formation for central London and Essex (Ellison et al., 2004)

\section{Shrinkage \& Swelling}

All clays are subject to shrinkage and swelling, but those with a higher proportion of expansive clay minerals, such as smectite, are more prone. The clay within the London Clay Formation is dominantly illite/smectite and is particularly susceptible to shrink-swell behaviour; it is generally accepted to be highly plastic (Driscoll, 1983; Cripps \& Taylor, 1986 and Reeves et. al., 2006), gradually increasing in plasticity from west to east in the London Basin by approximately 30\% (Burnett \& Fookes, 1974). The depth to which shrinkage and swelling occurs is usually confined to the active zone (upper $1.5 \mathrm{~m}$ ) where moisture change is most likely to occur, unless this zone is extended by the presence of tree roots (Driscoll, 1983). In a study of subsidence claims, related to shrink-swell clays, the London Clay is described as "the most commonly encountered problem soil" (Crilly, 2001).

\section{Volume Change Potential}

The Volume Change Potential (VCP) of a soil is the relative change in volume to be expected with changes in soil moisture content and is reflected by shrinking and swelling of the ground. That is, the extent to which the soil shrinks as it dries out, or swells when it gets wet. However, despite the various available test methods for determining these two phenomena (e.g. BS 1377, 1990: Part 2, tests 6.3 \& 6.4, Shrinkage Limit and 6.5, Linear Shrinkage and Part 5, test 4, Swelling Pressure) (British Standards Institution, 1990), they are rarely employed in the course of routine site investigations in the UK. Hence, few data are available for data-basing the directly measured shrink-swell properties of the major clay formations. Consequently, reliance is placed on estimates based on index parameters, namely, liquid limit, plastic limit, plasticity index, and density (Reeve et al., 1980; Holtz \& Kovacs, 1981; Oloo et al., 1987). No consideration has been given to the saturation state of the soil and therefore to the effective stress or pore pressures within it.

The most widely used parameter for determining the shrinkage and swelling potential of a soil is the Plasticity Index $\left(\mathrm{I}_{\mathrm{P}}\right)$. Such plasticity parameters, being based on remoulded specimens, cannot precisely predict the shrink-swell behaviour of an in-situ soil. However, they do follow properly laid down procedures, being performed under reproducible conditions to internationally recognised standards (Jones, 1999). A 'Modified Plasticity Index’ ( $\mathrm{I}_{\mathrm{P}}$ ') is proposed in the Building Research Establishment Digest 240 (1993) for use 
where the particle size data, specifically the fraction passing a $425 \mu \mathrm{m}$ sieve, is known or can be assumed as 100\% passing (BRE, 1993). The Modified $\mathrm{I}_{\mathrm{P}}$ ' takes into account the whole sample and not just the fines fraction, it therefore gives a better indication of the 'real' plasticity value of an engineering soil:

$$
I p^{\prime}=\operatorname{Ip} \times \frac{\%<425 \mu m}{100}
$$

Where: Ip’ is 'Modified’ Plasticity Index

Ip is 'Standard' Plasticity Index

\section{Data source}

A meaningful assessment of the shrink-swell potential of the London Clay across its entire outcrop requires a considerable amount of high-quality and well-distributed spatial data, of a consistent standard throughout. This was achieved by utilising the large body of index test data stored in the British Geological Survey's National Geotechnical Properties Database. At the time of this study, the national database contained data from more then 61,000 boreholes, comprising nearly 280,000 geotechnical samples, with over 84,000 containing relevant plasticity (Ip) data. Of these, 11,879 were determined for London Clay. Figure 2 shows the distribution of these data across England and Wales.

Figure 2 - Plasticity Index data distribution across England and Wales contained in the BGS National Geotechnical Properties Database

\section{Statistical analyses}

The data were validated by removing negative values, duplicate values, data-entry error values and those with no ground level, or inaccurate co-ordinate values before statisticallybased evaluations were made. This reduced the number of 'acceptable' plasticity values to 11,366. To quantify the Volume Change Potential of the London Clay a preliminary statistical evaluation of the $\mathrm{I}_{\mathrm{P}}$ ' values was carried out to determine the overall range of the data values with respect to their locations across the outcrop. This was carried out by plotting $\mathrm{I}_{\mathrm{P}}$ ' values against their Easting and Northing positions (Figures 3a and 3b) to determine if a west-east trend of increasing plasticity, as reported by Burnett \& Fookes (1974), or any northsouth trend was evident. By comparing these plots with a distribution plot of the plasticity data over the London Clay outcrop (Figure 4) it was possible to assess the overall variations of $\mathrm{I}_{\mathrm{P}}$ ' within the London Clay, and, in addition, to recognise five distinct areas within the outcrop as reflected by the number and value of the data points. Of the five recognised areas, Area 1 corresponds to the Hampshire Basin (Hampshire, Dorset, West Sussex and the Isle of Wight), Area 2 (west of London) covers most of Berkshire and Surrey, Area 3 covers Greater London, Hertfordshire, south Essex and Kent and Area 4 covers the rest of Essex and Suffolk, an area largely overlain by Glacial Till deposits. Area 3 was split into 3a (central London) and 3b (east of London) to deal with the data in this area more effectively. 
Figures 3a and 3b - Spread of data samples in West-East and North-South directions

Figure 4 - Distribution of plasticity data (Ip') across London Clay outcrop

Summary statistics for all 11,366 data samples across the London Clay outcrop and for the data within each of the five sub-areas are presented in Table 1. These include a count of the number of $\mathrm{I}_{\mathrm{P}}$ ' data points in each area, the minimum, maximum, mean, mode and median values and a series of inter-quartile values, including the upper quartile, the lower quartile values. These statistics are illustrated in the form of extended box and whisker plots (Figures 5 and 6) and histograms (Figure 7). Extended box plots are constructed from the $0.5^{\text {th }}, 2.5^{\text {th }}$, $10^{\text {th }}, 25^{\text {th }}, 50^{\text {th }}, 75^{\text {th }}, 90^{\text {th }}, 97.5^{\text {th }}$ and $99.5^{\text {th }}$ percentiles of the data sets. The selected percentiles have been chosen as a compromise between practical geotechnics and statistical rigour (Hallam, 1990).

Table 1 - Statistical analysis of $\mathbf{I}_{\mathbf{P}}$,

\begin{tabular}{ccccccc}
\hline & ALL & AREA1 & AREA2 & AREA3a & AREA3b & AREA4 \\
count & 11366 & 825 & 1857 & 7460 & 1020 & 204 \\
\hline min & 1 & 1 & 3 & 3 & 5 & 9 \\
0.005 & 11 & 6 & 8 & 16 & 12 & 9 \\
0.025 & 21 & 11 & 19 & 25 & 24 & 20 \\
0.1 & 30 & 20 & 28 & 33 & 37 & 27 \\
0.25 & 37 & 26 & 35 & 39 & 44 & 38 \\
median & 44 & 35 & 42 & 45 & 50 & 47 \\
0.75 & 50 & 44 & 48 & 50 & 56 & 53 \\
0.9 & 55 & 50 & 53 & 54 & 61 & 58 \\
0.975 & 62 & 56 & 59 & 62 & 68 & 64 \\
0.995 & 70 & 64 & 66 & 70 & 74 & 69 \\
max & 90 & 83 & 76 & 90 & 83 & 70 \\
mean & 43 & 35 & 41 & 44 & 49 & 45 \\
mode & 45 & 26 & 44 & 45 & 50 & 51
\end{tabular}

Figure 5 - Structure of extended box plots for 'normal' distribution of data values

Figure 6 - Extended Box \& Whisker plots of $I_{P}$ ' data values for the London Clay, by Area

Although, statistically, the median ( $50^{\text {th }}$ percentile) value would normally be used as the most representative of the shrink-swell behaviour of the London Clay outcrop, it was determined that in order to portray the 'worst-case' scenario, and represent a greater proportion of the data, the upper quartile $\left(75^{\text {th }}\right.$ percentile) value would be used. The calculated upper quartile value of $\mathrm{I}_{\mathrm{P}}$ ' based on all sample data across the entire London Clay outcrop was 50\%. 
The Volume Change Potential, VCP, for all areas, was calculated from the statistically analysed $\mathrm{I}_{\mathrm{P}}$ ' data and a classification made based on the upper quartile values. The subdivisions are summarised in Table 2 (based on the classification of the Building Research Establishment, 1993).

Table 2 - Classification of Volume Change Potential (after Building Research Establishment, 1993)

\begin{tabular}{ccl}
\hline Classification & \multicolumn{1}{c}{ IP' (\%) $^{\prime}$} & VCP \\
\hline A & $<10$ & Non Plastic \\
B & $10-20$ & Low \\
C & $20-40$ & Medium \\
D & $40-60$ & High \\
E & $>60$ & Very High \\
\hline
\end{tabular}

The $\mathrm{I}_{\mathrm{P}}$ ' values for the 11,366 data points were each allocated a VCP classification ranging from 'Non-Plastic' to 'Very High' in accordance with Table 2. The VCP for the whole outcrop (Ip' = 50\%) was classified as 'High'. All five areas within the outcrop were also classified as 'High', having Ip’ values in the range $44-56 \%$ (Table 1 and Figure 6).

Table 3 - Range and amount of Volume Change Potential calculated for each Area

\begin{tabular}{ccccccc}
\hline \multirow{2}{*}{ VCP } & \multicolumn{6}{c}{ PERCENTAGE OF SAMPLES PER CLASS } \\
\cline { 2 - 7 } & ALL & AREA 1 & AREA 2 & AREA 3a & AREA 3b & AREA 4 \\
\hline N/P & $<1$ & 2 & 1 & $<1$ & $<1$ & 1 \\
LOW & 2 & 7 & 2 & 1 & 1 & 1 \\
MEDIUM & 29 & 53 & 38 & 27 & 12 & 26 \\
HIGH & 64 & 37 & 57 & 68 & 72 & 63 \\
VERY HIGH & 4 & 1 & 2 & 4 & 14 & 8 \\
\hline
\end{tabular}

Table 3 shows the VCP calculated by area for the London Clay. Overall, 68\% of the samples have a VCP ranging from High to Very High. The results also show a distinct difference between the Hampshire (Area 1) and London basins (Areas 2 to 4), and across the London basin itself. Over $50 \%$ of the samples from the Hampshire basin (Area 1) fall into the Medium VCP classification category compared to less than $30 \%$ for the formation as a whole. In the London basin there is a gradual increase in plasticity from west to east. Area 2 (covering most of Berkshire and Surrey, to the west of London) shows 59\% of the samples fall within the High to Very High VCP classification. This increases to $72 \%$ in Area 3a (Greater London and Hertfordshire) and to 86\% in Area 3b (south Essex and Kent, east of London), dropping to 71\% in Area 4 (Essex and Suffolk, north-east of London). There is an increase in the upper quartile $\mathrm{I}_{\mathrm{P}}$ ' values between the Hampshire and London basins, and a similar increase in Ip', from west to east, across the London basin.

Plots of London Clay Ip' values against depth for Areas 2 to 4 are presented in Figure 8. These profiles show the sample data based on their height above the base of the London Clay. They are represented this way in accordance with how the stratigraphical units (A to D and 
Claygate Member) were determined by King (1981) and Ellison, et al. (2004). The top and base of the London Clay were mapped using data from boreholes held at the British Geological Survey (BGS) and compiled from various BGS applied mapping projects centred in and around London and the Thames Gateway. The Digital Terrain Model (DTM) on which the surface elevations for the boreholes is based was acquired from 'NextMap' data, and the outcrops were mapped from BGS 1:250K digital geological dataset (DigMap250).

Figure 8 - London Clay I ' vs. Depth Profiles (by Area)

The profiles in Figure 8 show that, for Area 2, 95\% of the data lie in the Medium to High VCP classification range ( $\mathrm{I}_{\mathrm{P}}{ }^{\prime}=25$ to 55\%) with little variation throughout the formation, although Hight et al. (2007) would suggest that there was a slight increase in the plasticity upwards. For Area 3a 72 percent of the data lies in the High to Very High classification range ( $\mathrm{I}_{\mathrm{P}}{ }^{\prime}>40 \%$ ) but reveal an increase in plasticity moving upwards from the base of the London Clay, as seen by Pantelidou \& Simpson (2007). For Area 3b 86 percent of the data also lie in the High to Very High category ( $\mathrm{I}_{\mathrm{P}}$ ' $>40 \%$ ) throughout the formation, but reveal a trend of increasing plasticity into Unit $\mathrm{D}$, followed by slightly decreasing plasticity towards the top of the Claygate Member. For Area 489 percent of the data lie within the Medium to High VCP classification range. Distributed mainly within the lowermost $50 \mathrm{~m}$ of the formation, the data for this area show a possible trend of generally increasing plasticity away from the base of the formation. However, there are too few data values (204) for this perceived trend to be truly meaningful.

In the London district, the five lithostratigraphical units (A to D and Claygate Member) are illustrated in Figure 1. These were identified by Ellison, et al. (2004), based on earlier work by King (1981) and extensive borehole information, and later by De Freitas \& Mannion (2007). The boundaries of these units are also indicated in Figure 8 for the profiles of Areas 3a and $3 \mathrm{~b}$ that equate to the London district described by Ellison et al. (2004). Area 3a shows a slight trend of increasing plasticity moving upwards from the base of the formation, from units A to C towards Unit D. The plasticity data for Area 3b shows a more or less constant trend throughout units $\mathrm{A}$ to $\mathrm{C}$ but shows a slight decrease in plasticity towards the uppermost Claygate Member, reflecting the change in lithology to a more sandy facies. However, with large amounts of data, covering such a wide area, it is difficult to determine the changes in plasticity, with stratigraphy, to any great detail. Therefore, another method of examining the data, such as 3-D modelling, is required.

\section{Spatial Interpretation}

As shown above, variations in plasticity with area and with depth can be depicted using purely statistical methods. However, the profiles show that these methods do not reveal the true multi-dimensional variation of the formation. To do this a more suitable method of modelling the data, such as 3-D interpolation, is required.

Interpolation estimates values at unknown locations based on known samples (Lam, 1983). There are two main outcrops of the London Clay Formation, the Hampshire Basin (Area 1) and the London Basin (Areas 2, 3a \& 3b and 4). However, there is little scientific justification for interpolating between the two outcrops where there are no data, as the 'gap' between the 
basins is too large and this would only obscure the model. Furthermore, the data available for the Hampshire Basin is less extensive. Therefore, only those areas in the London Basin where the data were most suitable in terms of both number of values and their distribution were analysed in this manner.

The Inverse Distance Weighting (IDW) interpolative technique (Jones, 1997) was applied to the London Basin dataset to determine whether any spatial trend in the plasticity of the London Clay was evident. The IDW technique assumes that the weight of a value decreases as the distance increases from the prediction location. The IDW technique was applied to the dataset using the geostatistical analysis extension in ESRI ArcMap 9.1 Geographical Information system (GIS). IDW is an exact interpolator in that it takes little account of any underlying trend in the data. This means that the technique should highlight spatial variations in the dataset, but not be influenced by them.

IDW is a 'local', deterministic method of interpolation. 'Global' methods of interpolation use all available data to make predictions for the whole area of interest, but local interpolators (such as IDW) use a small area around a point to make its predictions. IDW techniques combine the notion of proximity whilst introducing gradual change based on the trend surface. The technique's principal weakness is that it makes no assessment of prediction errors and it can produce a 'bulls-eye' effect around sample locations, especially where data samples are sparsely distributed. To remove this error, the methodology applied to the London Clay data set described here forced the interpolation to include at least five nearest neighbour samples.

To identify whether any directional trend existed in the $\mathrm{I}_{\mathrm{P}}$ ' values for the London Clay, the outcrop covering the London Basin (areas 2, 3a \& 3b and 4) was analysed, observing all available sample points, and ignoring variations with depth. However some sizable gaps in the distribution of samples across the outcrop (Figure 3) were likely to influence the interpolation model.

The resulting spatial analysis using the IDW interpolative technique showed that, although there are localised exceptions, possibly a result of the 'bulls-eye' effect described earlier, the VCP tends to increase from the western part of the London Basin towards the east, and the mouth of the river Thames (Figure 9). The interpolation shows that in the central and eastern parts of the London Basin, the London Clay is more plastic than in the western part.

\section{Figure 9 - IDW interpolation for all samples using mean IP' at each sample location}

However, there are problems with this interpolation model relating to the sample distribution. For example, an area of the outcrop that encompasses Chelmsford suggests a lower plasticity than the area surrounding it. Whilst this may be true, the validity of the model's prediction is questionable given that relatively few samples exist within this area.

This poses several questions. For example, should the model be generated for the whole outcrop, or for just those locations within a specified and statistically influential distance from known sample locations? Should the average Ip' value of the borehole be taken, or does the model change considerably if the $\mathrm{I}_{\mathrm{P}}$ ' at specified depths are taken into consideration?

To generate a statistically defined model, an area with a large amount of well-spaced data at variable depth is required. To meet this requirement, Areas 3a and 3b were combined giving a total of 8,416 values at depths ranging from 0.25 to $150 \mathrm{~m}$. Ground movements associated 
with shrinkage and swelling affect the soil in the near-surface zone, significant activity occurring from surface to about $5 \mathrm{~m}$ but exceptionally to $10 \mathrm{~m}$. Taking this into account interpolated models were then generated for depth zones of 0 to $5 \mathrm{~m}, 5$ to $10 \mathrm{~m}$ and $>10 \mathrm{~m}$, respectively (Figure 10a-c).

Figure 10 - IDW interpolation of VCP for combined Areas 3a and $3 b$ for three depth zones, a) 0 to $5 \mathrm{~m}$, b) 5 to 10m, and c) >10m [Colour key as in Figure 9]

Once the depth intervals were established an interpolation technique could be applied to each sample subset. Although there are still small areas with sparse data, most notably around Brentwood within the 0 to $5 \mathrm{~m}$ depth zone, there appears to be little variation across the outcrop, with the majority of the area classified as High VCP (Figure 10a). As the sample depth increases (5 to10m) there appears to be an area to the east, around Burnham-onCrouch, that shows elevated plasticity, classified as Very High VCP (Figure 10b). This trend appears to continue at depths below 10m (Figure 10c).

Although of interest, depth-slicing the data in this manner does not give a true representation of the changes in VCP with depth within the London Clay. Interpolations were also carried out at $1 \mathrm{~m}$ intervals and, although giving a better representation of the data, they still do not reveal true 3-D changes.

\section{3-D Modelling}

To construct an even more representative model of spatial VCP variations in the London Clay utilisation of a more sophisticated 3-D modelling and visualisation package is necessary; for example Earth Decision Suite GoCAD ${ }^{\mathrm{TM}}$ 2.1.6. To maintain the statistical integrity of the model, the data from areas 3a and 3b were again used. A Digital Terrain Model (DTM) of the London Basin was created from 'NextMap' data that was reduced in resolution and size to cope with the huge amount of data. The borehole and surface sample information were then 'hung' from the DTM to give it an accurate position below ground level.

To visualise the data as accurately as possible, it was decided to create two types of models, Voxet and S-Grid. A Voxet object is a 3-D regular grid consisting of volume elements called voxels, or cells. It can contain multiple property information for a model. An S-Grid object is a flexible, 2-D, or 3-D, grid that can be fitted between two boundary horizons to model a volume. Culshaw (2005) gave an example of this approach using SPT ' $N$ ' Value data for glacial till in the Manchester/Salford (UK) area. It can also contain multiple property information, but fits the boundaries of the data more accurately. 
The Voxet model was created from the bounding dimensions of the combined Area 3, using the London Basin DTM as the upper limit. The modified $\mathrm{I}_{\mathrm{P}}$ ' values from this area were then 'hung' from the DTM to create the control points. The grid was initialised using X, Y and Z planes (Figure 11) and interpreted using a multigrid (all direction) interpolation (Figure 12), which was found to be the method most suited to data visualisation.

Voxet models are based on rectangular grids and, although the areas outside Area 3 could be masked out, this means the interpolation is still not truly accurate. It does, however, provide an improved interpretation of VCP with depth across the outcrop.

Figure 11 - Voxet visualisation (X, Y) for area 3, centred on Childerditch, Essex (blue-medium, greenhigh, yellow/red or purple-very high VCP)

Figure 12 - Multigrid interpolation of Voxet data for area 3, showing $5 \mathrm{~m}$ depth surface (blue-medium, green-high, yellow/red-very high VCP)

\section{S-Grid Model}

An S-Grid model was created using the '3D grid reservoir builder' in GoCAD ${ }^{\mathrm{TM}}$ with the London Basin DTM set as the upper limit, the DTM -50m surface as the basal limit and the outcrop of Area 3 as the area boundary. The modified IP' values were draped onto the S-Grid to 'paint' the grid cells (each cell containing an $\mathrm{I}_{\mathrm{P}}$ ' value was transformed to that $\mathrm{I}_{\mathrm{P}}$ ' value). The grid was then initialised to the mean value (derived by the builder), giving all cells without a 'painted' $\mathrm{I}_{\mathrm{P}}$ ' value the mean value. The modified $\mathrm{I}_{\mathrm{P}}$ ' values were then interpolated and smoothed throughout the grid, giving a full 3-D image (Figure 13).

Figure 13 - Close-up of 3-D multigrid interpolation of area 3, showing full depth (x, y) sections down to $50 \mathrm{~m}$ surface (blue-medium, green-high, yellow/red-very high VCP)

The S-Grid provides the most seamless interpolation of the 8,416 modified IP' samples for the combined Area 3. It provides a visualisation that allows the $\mathrm{I}_{\mathrm{P}}$ ' values to be examined relative to ground level, as opposed to just seeing the trends within the data itself. Visualising the data with the DTM gives a greater sense of reality and perspective. Inverse Distance Weighting (IDW) allows only snapshots at different depth intervals but the S-Grid allows interactive and dynamic visualisations of the data at various depths and locations. Combining these GIS and 3-D modelling capabilities, prediction of plasticity and, hence, volume change potential, across the London Basin becomes a realistic prospect.

Again, there are some areas with few data but this does not appear to affect the overall model. As with the IDW model, little variation is seen in plasticity in the uppermost part of the London Clay, which falls mainly within the High VCP class (Figure 14a). However, as the depth increases to $8 \mathrm{~m}$ plus, an area of increased plasticity equating to a Very High VCP classification, can be seen in the east of the area (Figure 14b). At around 20m depth the VCP in the east remains Very High decreasing to Medium VCP in the west (Figure 14c). This trend continues to a depth of approximately $30 \mathrm{~m}$, beyond which the VCP in the east 
decreases from Very High to High. In the west an increasingly larger area remains at Medium VCP as the depth reaches 50m (Figure 14d).

Figure 14 - S-Grid interpolations for Area 3, showing surfaces at 0m, 8m, 20m and 50m (blue-medium, green-high, yellow/red-very high VCP)

Burnham-on-Crouch is in Area 3b and the Very High VCP occurs within Unit D of the London Clay. Assuming that the data and interpolation are correct, these variations are most likely to be related to the mineralogical composition of the clay. This may, for example, reflect an increase in smectite and/or a decrease in non-clay minerals, both of which would tend to result in increased plasticity. Mineralogical sample data to confirm these trends are not yet available but will form the basis of future work. 


\section{Conclusions}

- The calculated upper quartile ( $75^{\text {th }}$ percentile) value of Modified Plasticity Index ( $\left.\mathrm{I}_{\mathrm{P}}{ }^{\prime}\right)$ across the entire London Clay onshore outcrop is 50\%, indicative of High Volume Change Potential (VCP).

- Both the statistical and spatial analyses confirm a west to east trend of increasing plasticity and, hence, VCP, with some localised areas of Very High plasticity.

- The west to east increase in clay content and VCP relates directly to the palaeogeography of the area. The high VCP represents the more distal marine areas.

- 2-D representations based on statistical analyses show general trends; but with large amounts of data spread over a wide area, the detail is lost.

- The Inverse Distance Weighting (IDW) spatial modelling technique is affected by the data distribution, calling into question the validity of the predicted model.

- 3-D models, such as those calculated by S-Grid, provide a seamless interpolation, giving a visualisation that allows the $\mathrm{I}_{\mathrm{P}}$ ' values to be examined at a variety of depths relative to ground level.

- The results of the modelling have highlighted variations of VCP with depth in the London Clay across central and east London and south Essex (Areas 3a and 3b) as follows:

o Near-surface - Little variation, the VCP is High across the area.

o 8-20m - Increasing plasticity east of London, around the mouth of the Thames (Area 3b), VCP changes from High to Very High.

o 20-30m - Decrease in plasticity in central London (Area 3a), VCP changes from High to Medium. Plasticity remains the same in the east (Area 3b), VCP is Very High.

$0>30 \mathrm{~m}-$ Decrease in plasticity in east (Area 3b), VCP changes from Very High to High. Plasticity remains the same in central London (Area 3a), VCP is Medium.

- The analyses undertaken here indicate that 3-D modelling methods have considerable potential for predicting the spatial variation of VCP within the London Clay, and other clay soils with similarly large data sets, and warrant further development and trialling.

- The variation in VCP can be related to changes in the mineralogical composition of the London Clay. This will be the subject of a future publication.

\section{Acknowledgements}

This paper is published with the permission of the Executive Director of the British Geological Survey (NERC).

The authors would like to acknowledge the help and advice given by Kevin Northmore and Martin Culshaw, BGS.

NextMap digital terrain model from Intermap Technologies. 


\section{References}

Building Research Establishment 1993. Low-rise buildings on shrinkable clay soils: Part 1, Digest 240. Building Research Establishment. Watford.

British Standards Institution 1990. British Standard Methods of test for Soils for civil engineering purposes. Part 6. British Standards Institution. London.

Burnett, A.D. \& Fookes, P.G. 1974. A regional engineering geological study of the London Clay in the London \& Hampshire Basins. The Quarterly Journal of Engineering Geology, 7, 257-296.

Chandler, R.J. \& Apted, J.P. 1988. The effect of weathering on the strength of London Clay. Quarterly Journal of Engineering Geology and Hydrogeology, 21, 59-68.

Chisholm, A. 1984. Rising groundwater levels in London. M.Sc. Thesis. Imperial College, University of London.

Crilly, M. 2001. Analysis of a database of subsidence damage. Structural Survey, 19, No. 1, 7-15.

Cripps, J.C. \& Taylor, R.K. 1986. Engineering characteristics of British over-consolidated clays and mudrocks: I Tertiary deposits. Engineering Geology, 22, 349-376.

Culshaw, M.G. 2005. From concept towards reality: developing the attributed 3D geological model of the shallow subsurface. Quarterly Journal of Engineering Geology and Hydrogeology, 38, 231-284.

Curry, D. 1992. Tertiary. in Duff, P.McL.D \& Smith, A.J. (eds). Geology of England and Wales, 389-411.

Daley, B. 1999. Palaeogene sections in the Isle of Wight: a revision of their descriptions and significance in the light of research undertaken over recent decades. Tertiary Research, 19 (12), 1-69.

De Freitas, M.H. \& Mannion, W.G. 2007. A biostratigraphy for the London Clay in London. . Geotechnique, 57, No. 1, 91-99.

Driscoll, R. 1983. The influence of vegetation on the swelling and shrinking of clay soils in Britain. Quarterly Journal of Engineering Geology and Hydrogeology, 38, 93-105.

Ellison, R.A., Knox, R.W.O’B., Jolley, D.W. \& King, C. 1994. A revision of the lithostratigraphical classification of the early Palaeogene strata of the London Basin and East Anglia. Proceedings of the Geologists Association, 105, 187-197.

Ellison, R.A., Woods, M.A., Allen, D.J., Forster, A., Pharoah, T.C. \& King, C. 2004. Geology of London. Memoir of the British Geological Survey, Sheets 256 (North London), 257 (Romford), 270 (South London) and 271 (Dartford).

Forster, A. 1997. The engineering geology of the London area. British Geological Survey, Technical Report WN/97/27.

Hallam, J. R. 1990. The statistical analysis and summarisation of geotechnical databases. British Geological Survey, Technical Report WN/90/16.

Hight, D.W., Gasparre, A., Nishimura, S., Minh, N.A., Jardine, R.J. \& Coop, M.R. 2007. Characteristics of the London Clay from the Terminal 5 site at Heathrow Airport. Geotechnique, 57, No. 1, 3-18. 
Hight, D.W., McMillan, F., Powell, J.J.M., Jardine, R.J. \& Allenou, C.P. 2002. Some characteristics of London Clay. in Tan, T.S., Phoon, K.K., Hight, D.W. and Leroueil, S. (eds). Characterisation and engineering properties of natural soils, 851-908. Rotterdam: Balkema.

Holtz, R.D. \& Kovacs, W.D. 1981. An introduction to geotechnical engineering. PrenticeHall, New Jersey.

Jones, C.B. 1997. Geographical Information Science and Computer Cartography. First Edition, Longman Publishing, Harlow.

Jones L.D. 1999. A shrink/swell classification for UK clay soils. B.Eng. Thesis. Nottingham Trent University.

King, C. 1981. The stratigraphy of the London Clay and associated deposits. Tertiary Research Special Papers, 6, 1-158.

Knox, R.W. O’B. 1979. Igneous grains associated with zeolites in the Thanet beds of Pegwell Bay, N.E. Kent. Proceedings of the Geologists Association, 90, 55-60.

Lake, R.D., Ellison, R.A., Henson, M.R. \& Conway, B.W. 1986. Geology of the country around Southend and Foulness. Memoir of the British Geological Survey, Sheets 258 and 259.

Lam, N.S. 1983. Spatial Interpolation methods: A review. The American Cartographer, 10, 129-149.

Lerner, D.N. \& Barrett, M.H. 1996. Urban groundwater issues in the United Kingdom. Hydrogeology Journal, 4, No. 1, 80-89.

Mather, N. 1985. Groundwater attack at Old Street. M.Sc. Thesis. Imperial College, University of London.

Murray, J.W. \& Wright, C.A. 1974. Palaeogene foraminiferida and palaeoecology, Hampshire and Paris Basins and the English Channel. Palaeontology Special Paper, 14, 1129.

Oloo, S., Schreiner, H.D. \& Burland, J.B. 1987. Identification and classification of expansive soils. Proceedings of the $6^{\text {th }}$ International Conference on Expansive Soils, New Delhi, India, 23-29.

Pantelidou, H. \& Simpson, B. 2007. Geotechnical variation of London Clay across central London. Geotechnique, 57, No. 1, 101-112.

Rainey, T.P. \& Rosenbaum, M.S. 1989. The adverse influence of geology and groundwater on the behaviour of London Underground railway tunnels near Old Street Station. Proceedings of the Geologists Association, 100 (1), 123-134.

Reeve, M.J., Hall, D.G.M. \& Bullock, P. 1980. The effect of soil composition and environmental factors on the shrinkage of some clayey British Soils. Journal of Soil Science, 31, 429-442.

Reeves, G.M., Sims, I. \& Cripps, J.C. (eds) 2006. Clay Materials Used in Construction. Geological Society, London, Engineering Geology Special Publication, 21.

Sellwood, B.W. \& Sladen, C.P. (1981) Mesozoic \& Tertiary argillaceous units: distribution and composition. Quarterly Journal of Engineering Geology and Hydrogeology, 14, 263-275. 
Simpson, B., Blower, T., Craig, R.N. \& Wilkinson, W.B. 1989. The engineering implications of rising groundwater levels in the deep aquifer beneath London. C.I.R.I.A. Special Publication 69, C.I.R.I.A., London.

Skempton, A.W. \& DeLory, F.A. 1957. Stability of Natural Slopes in London Clay. Proceedings of the $4^{\text {th }}$ International Conference on Soil Mechanics, London, 378-381.

Smith, A. 1989. Geology of the Stanford-le-Hope district. (1:10,000 sheet TQ68SE; parts of 1:50,000 sheets 257, Romford \& 258/259, Southend \& Foulness) British Geological Survey. Technical Report No. WA/89/40.

Takahashi, A., Jardine, R.J. \& Fung, D.W.H. 2005. Swelling effects on mechanical behaviour of natural London Clay. Proceedings of the $16^{\text {th }}$ International Conference on Soil Mechanics, Osaka, 443-446. 
HAMPSTEAD HEATH

BOREHOLE

TO 28NE/198

[2645 8689]
CRYSTAL PALACE

BOREHOLE

TQ 37SW/671

[3379 7082]
STOCK

BOREHOLE

TL 70SW/1

[7054 0045]

$\gamma \log$

Claygate

Member
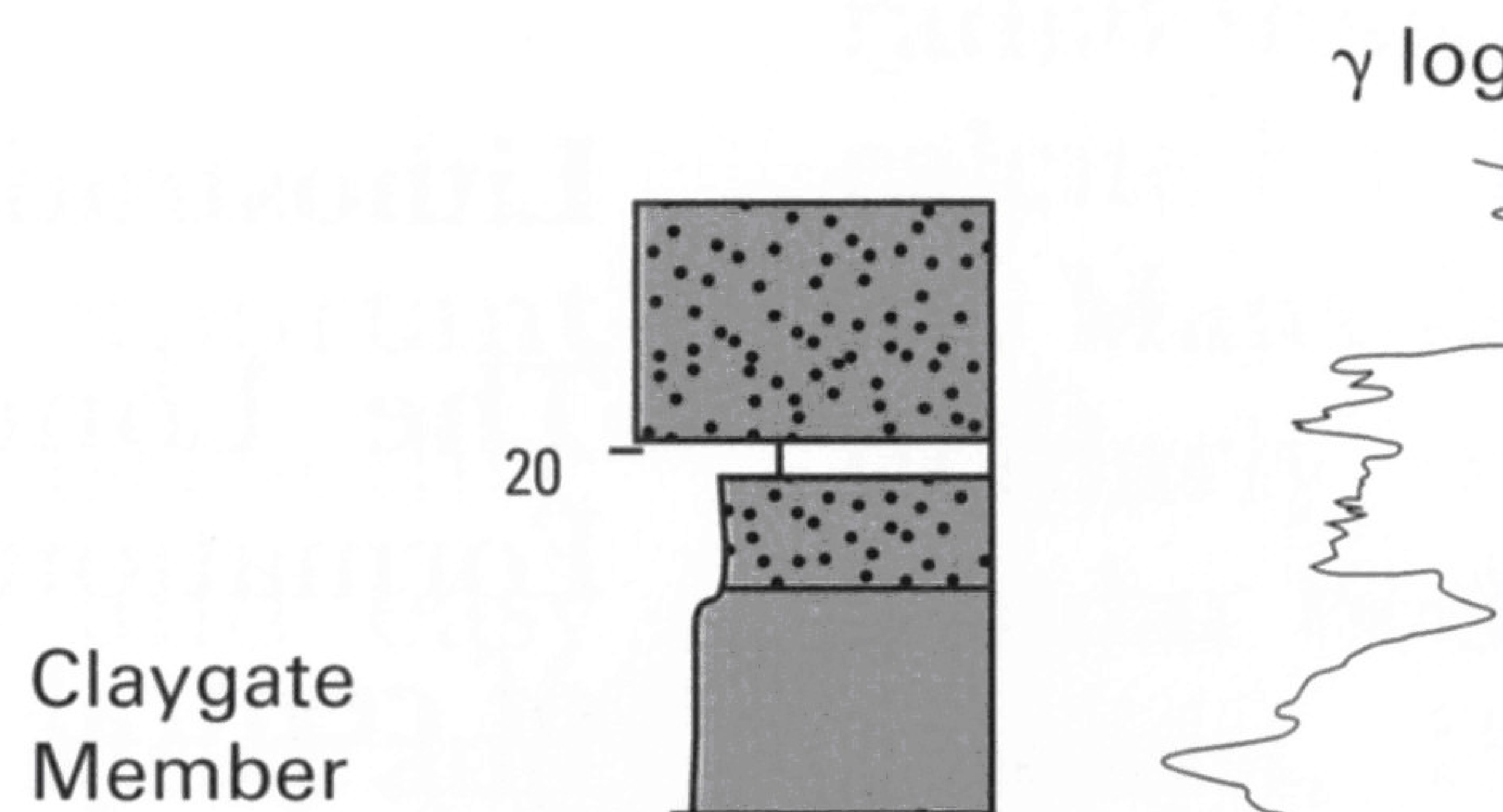

20

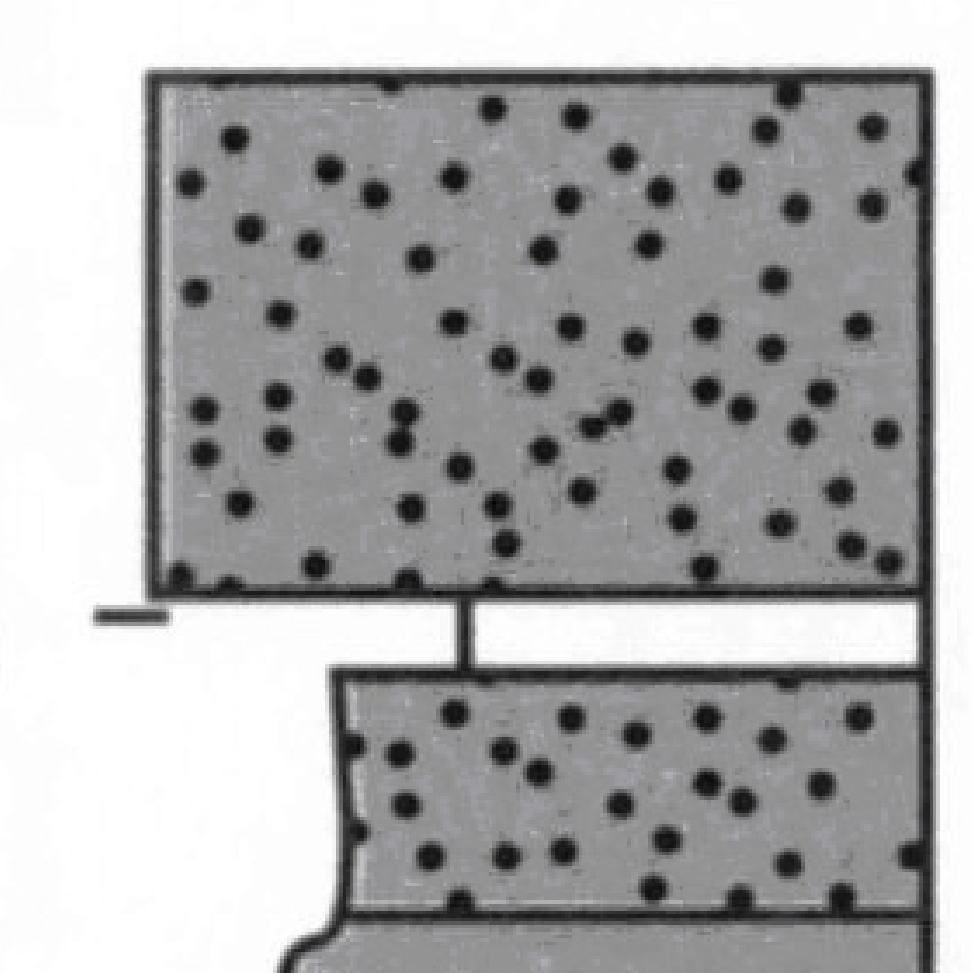

$\gamma \log$

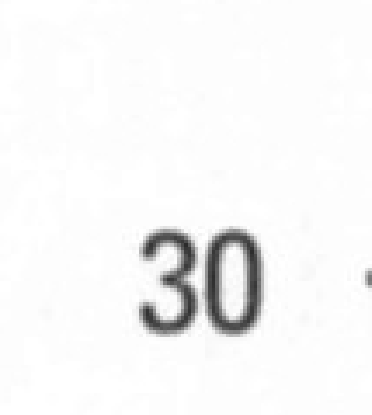

40

$50-$
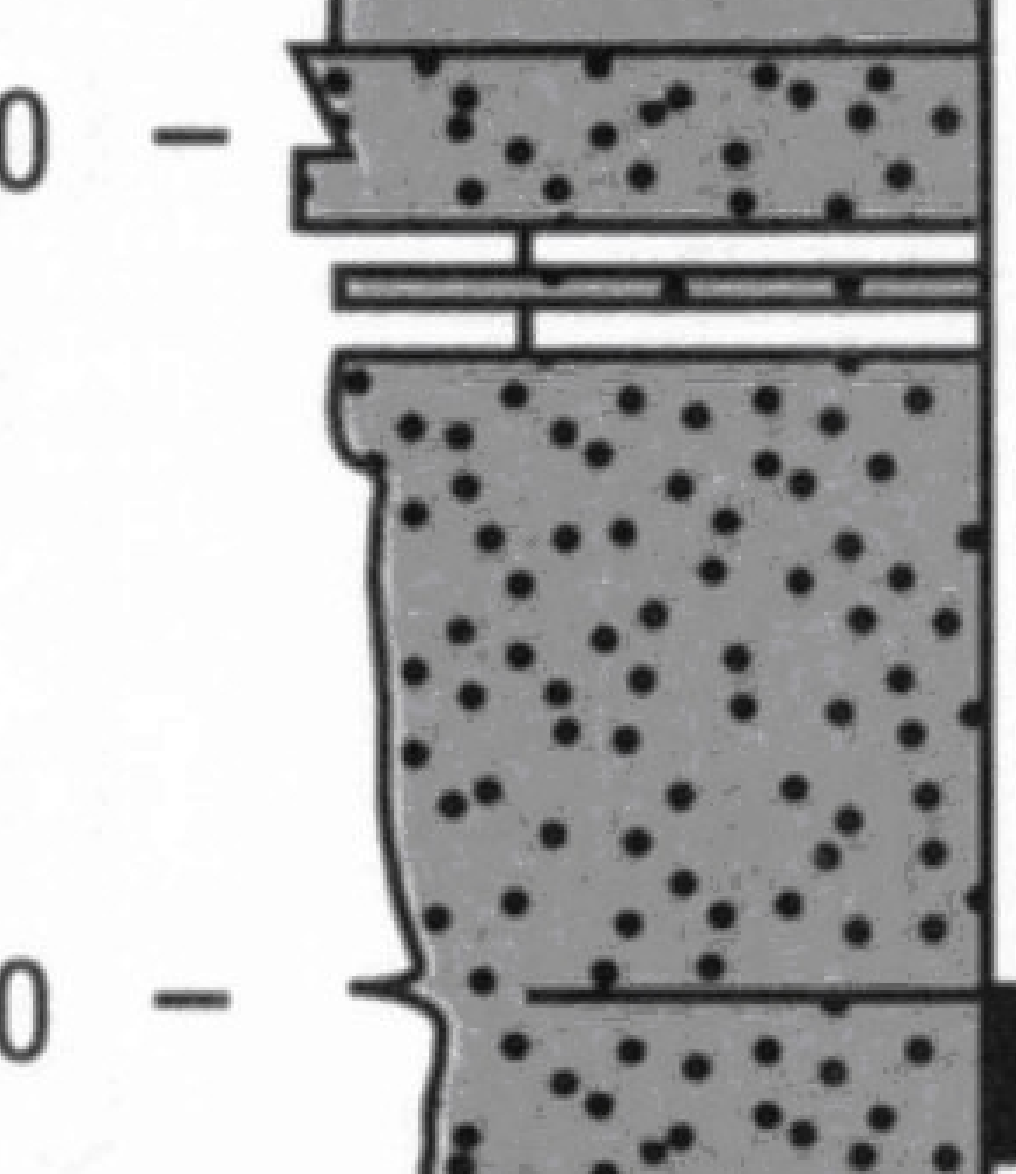

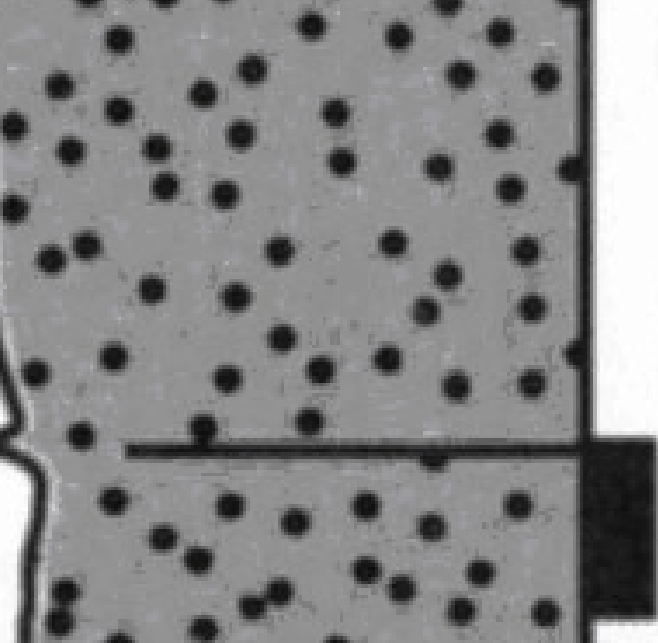

Unit D $60-$

Unit D $60-$
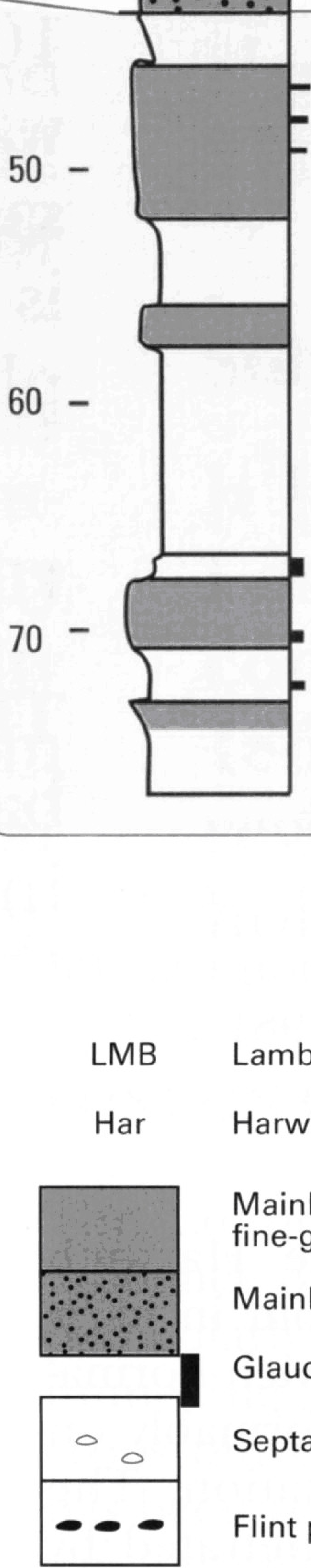

Lambeth Group

\section{Mainly silt and very} fine-grained sand

Mainly very fine-grained sand

Glauconite grains

Septarian nodule

Flint pebbles

Unit B

Unit A

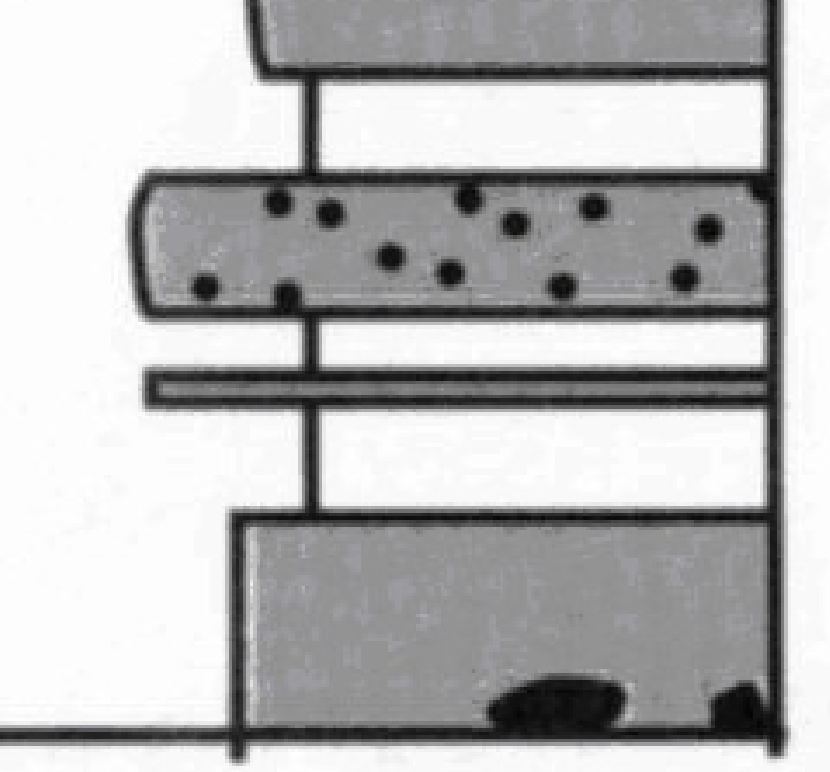




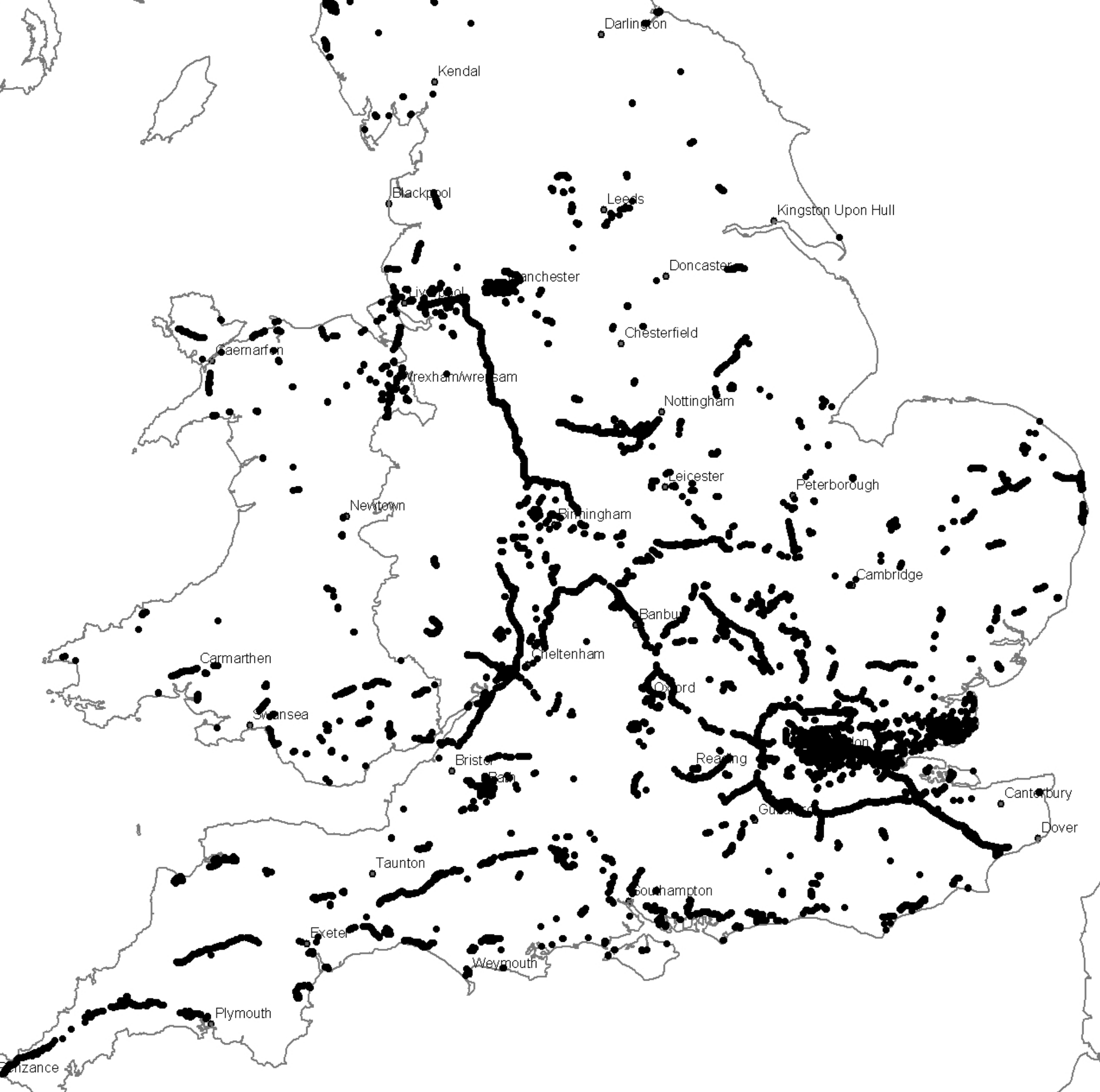




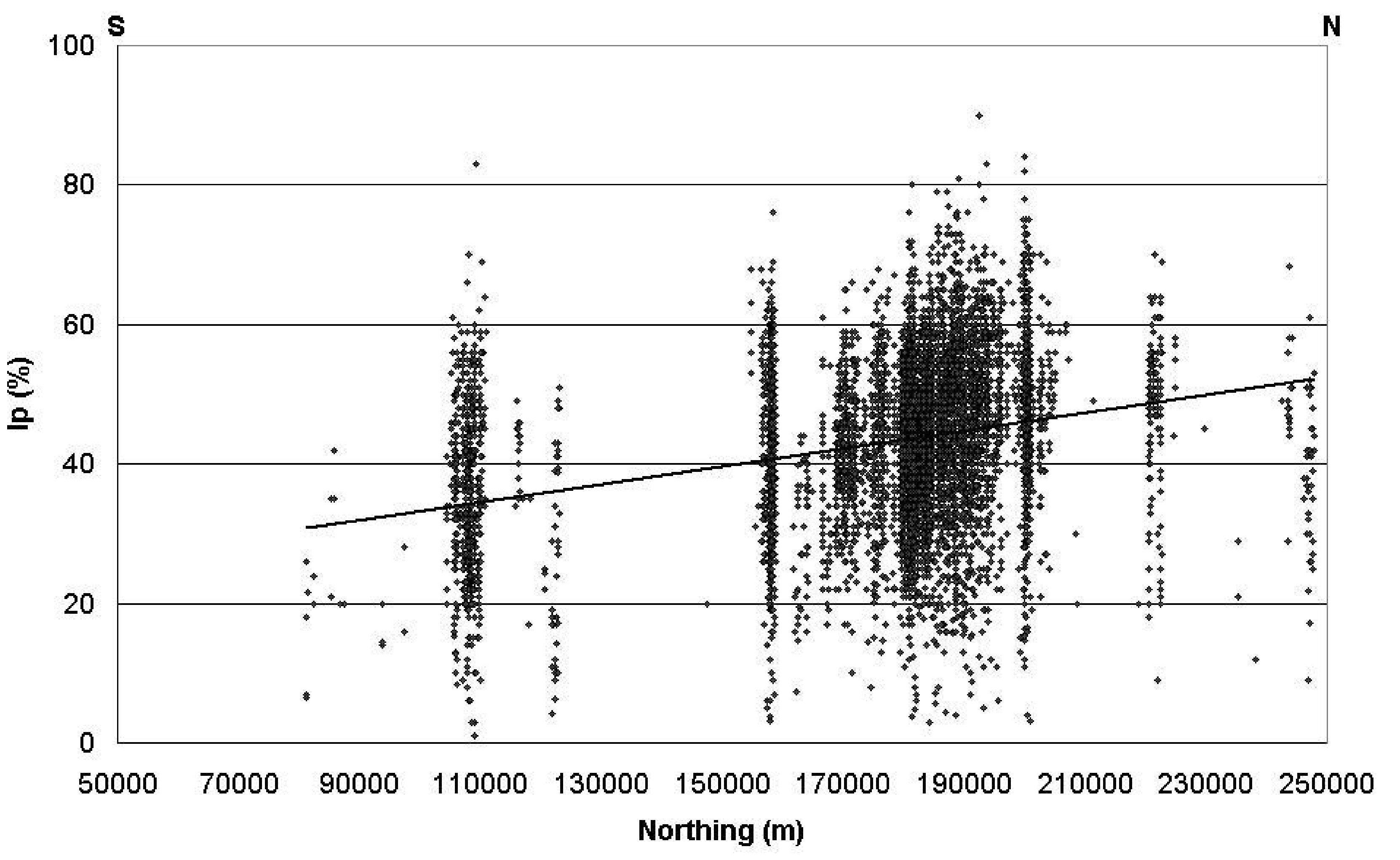




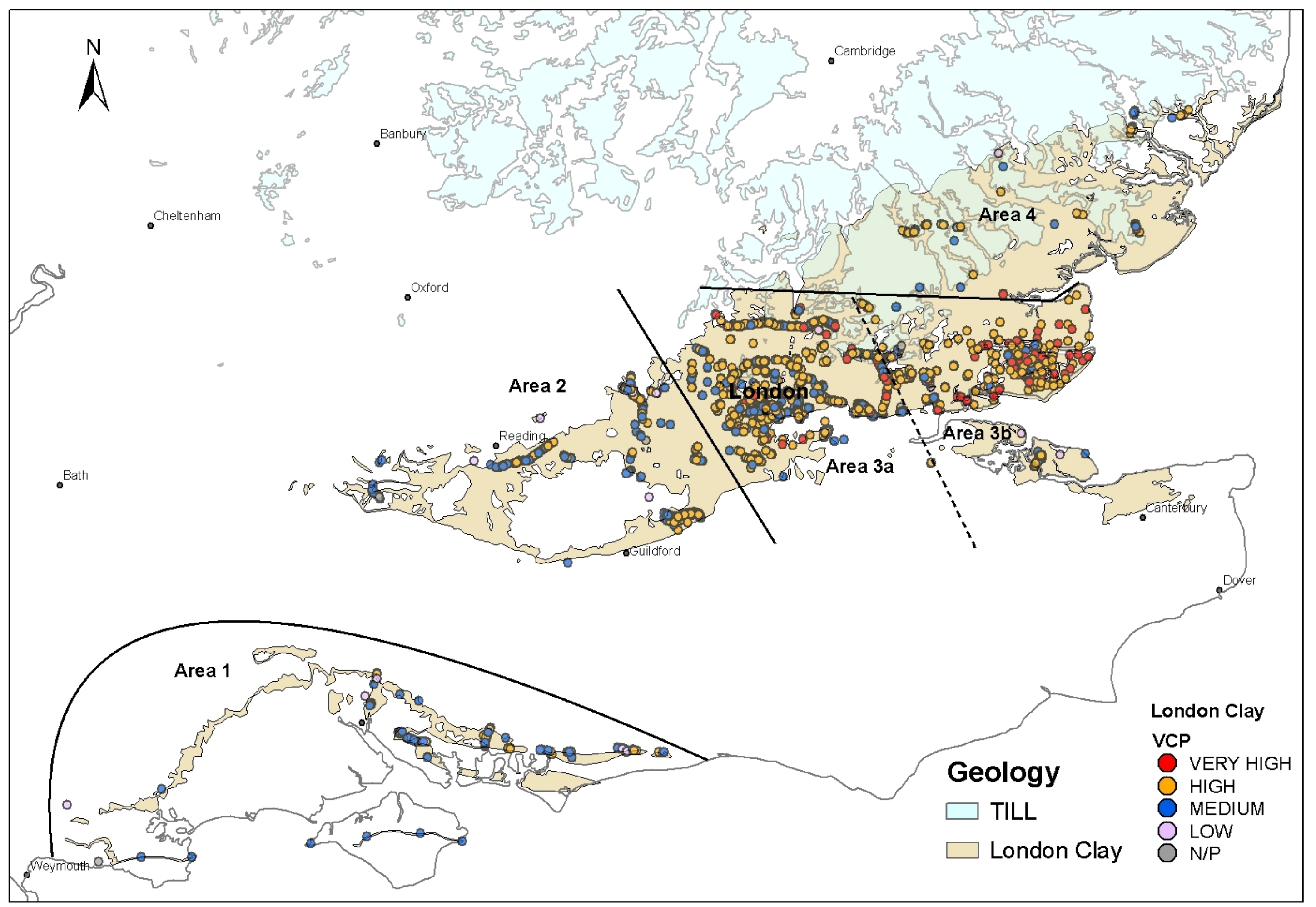




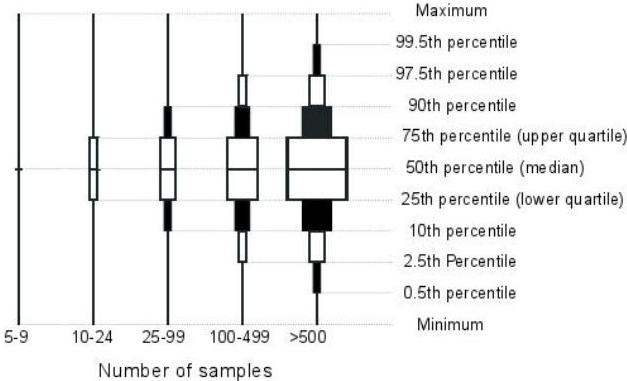


All

11366
Area1

825

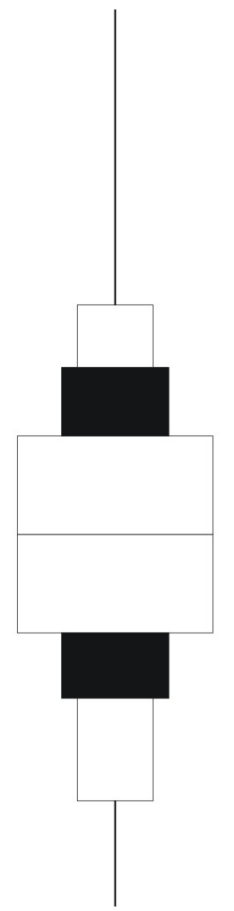

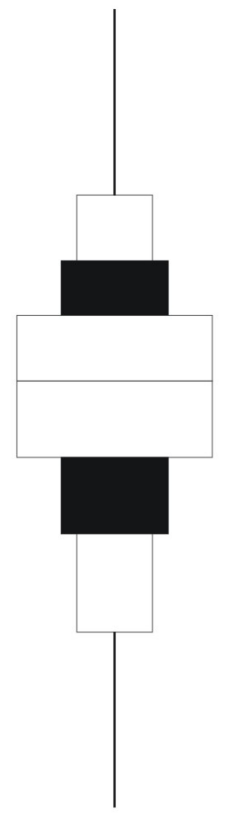

204
1020

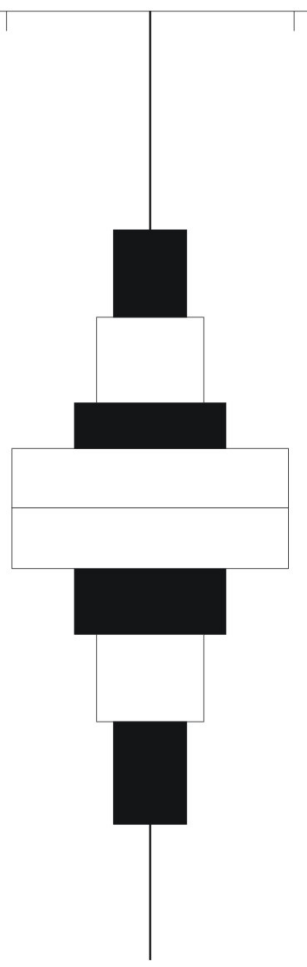

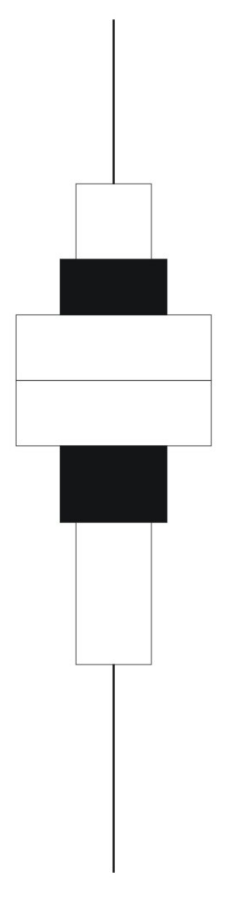

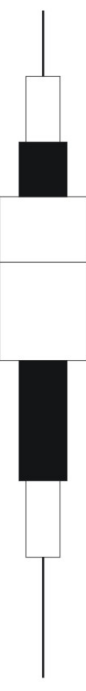

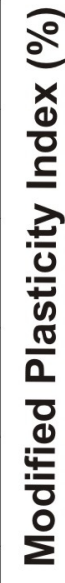




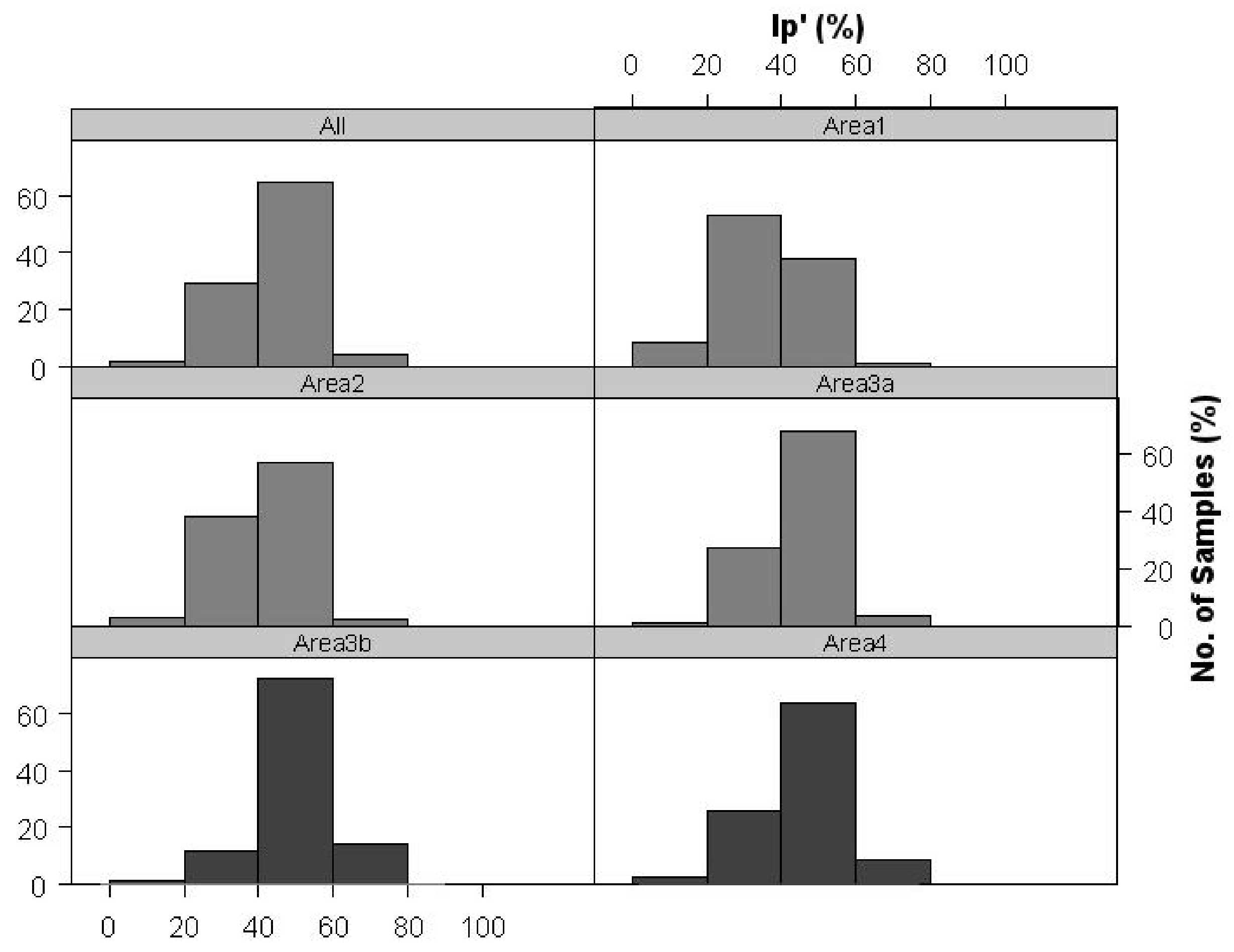



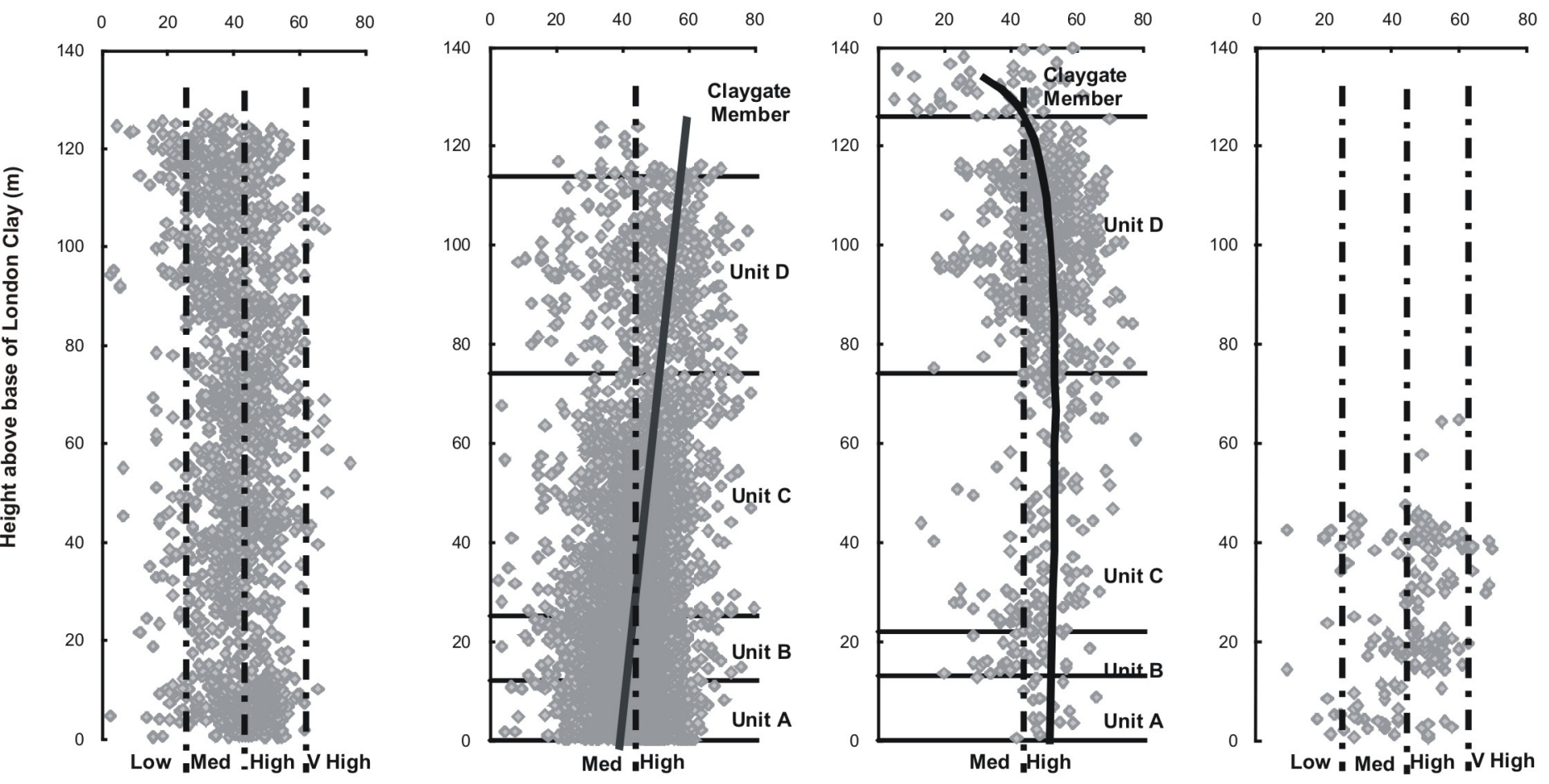


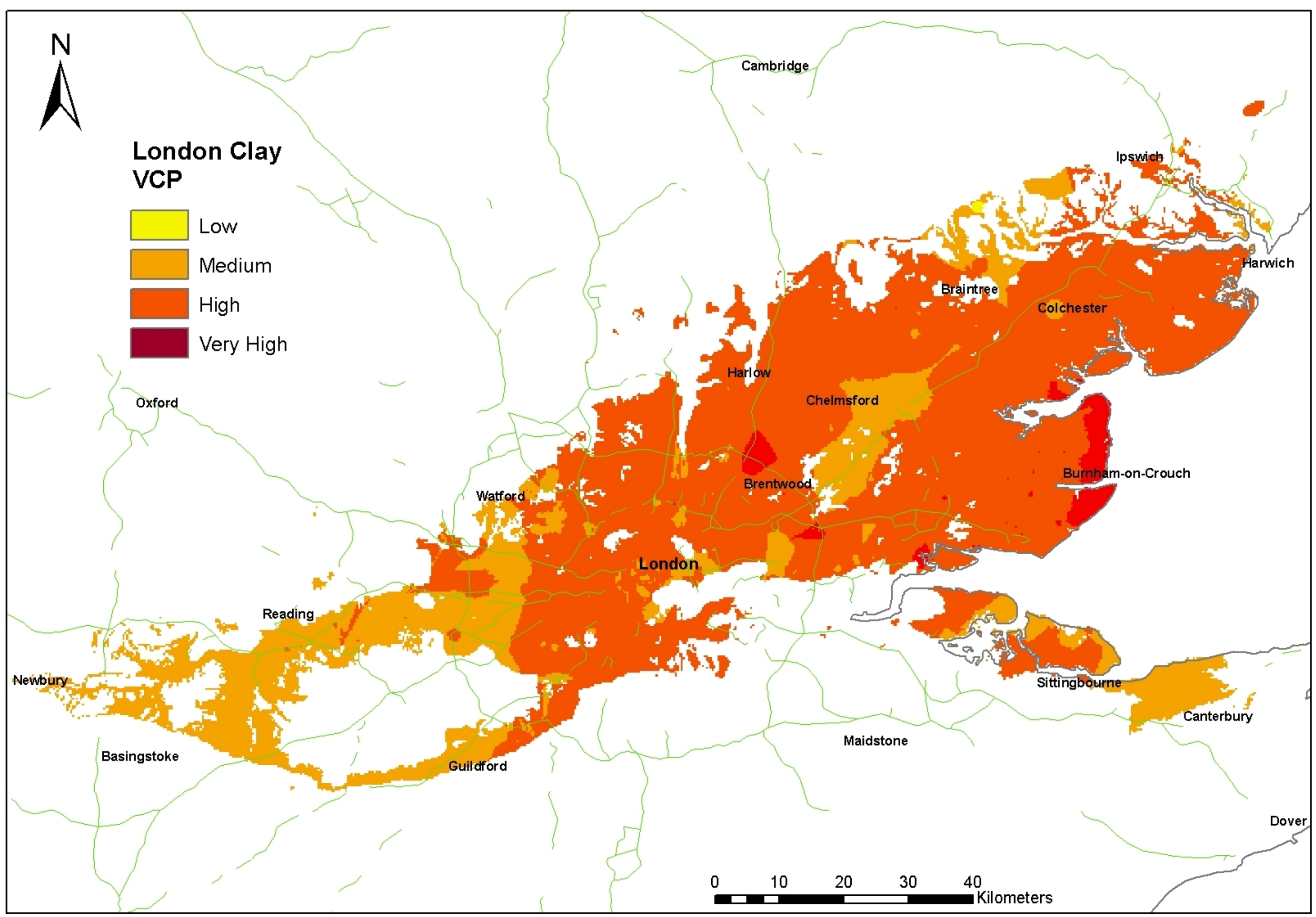




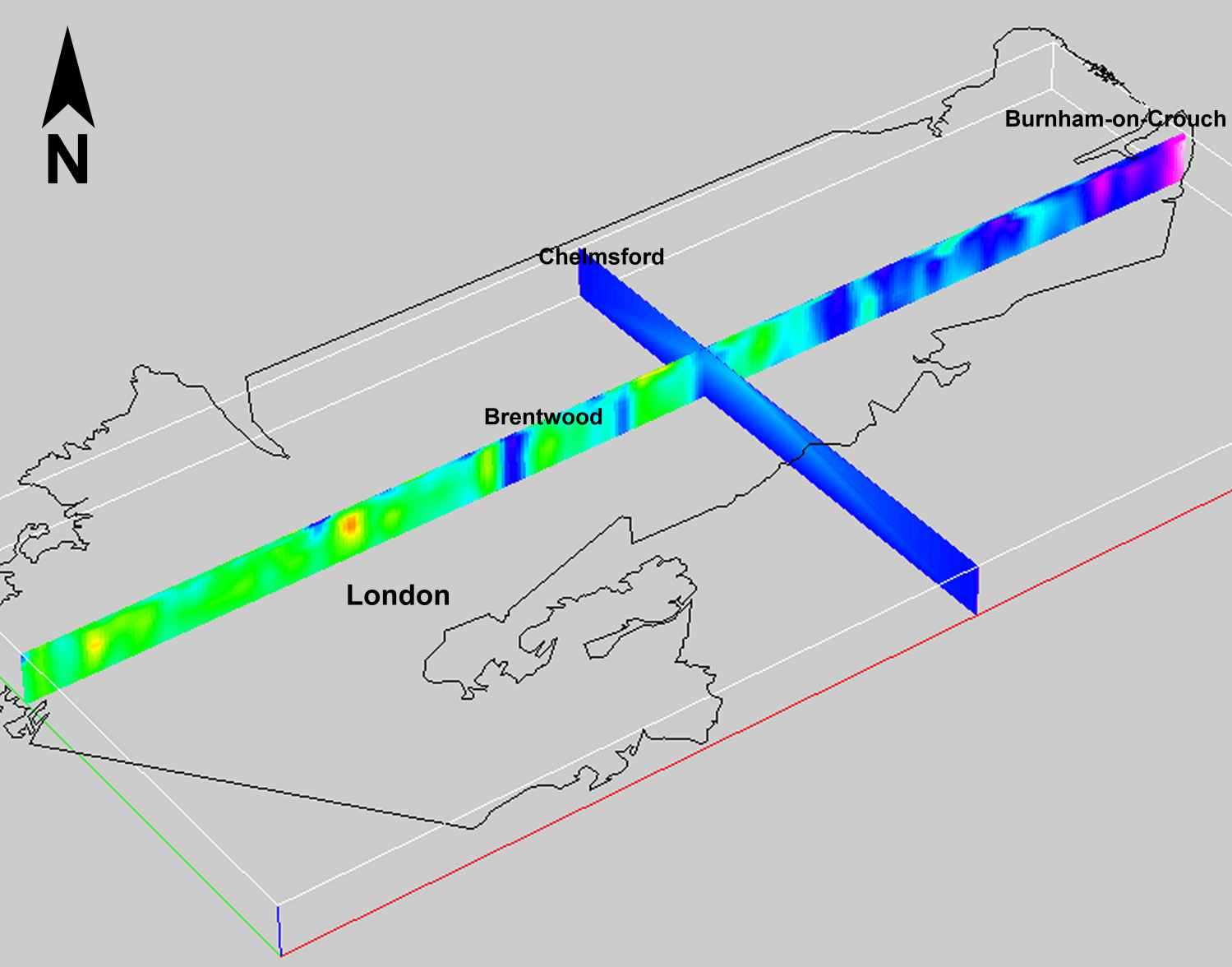




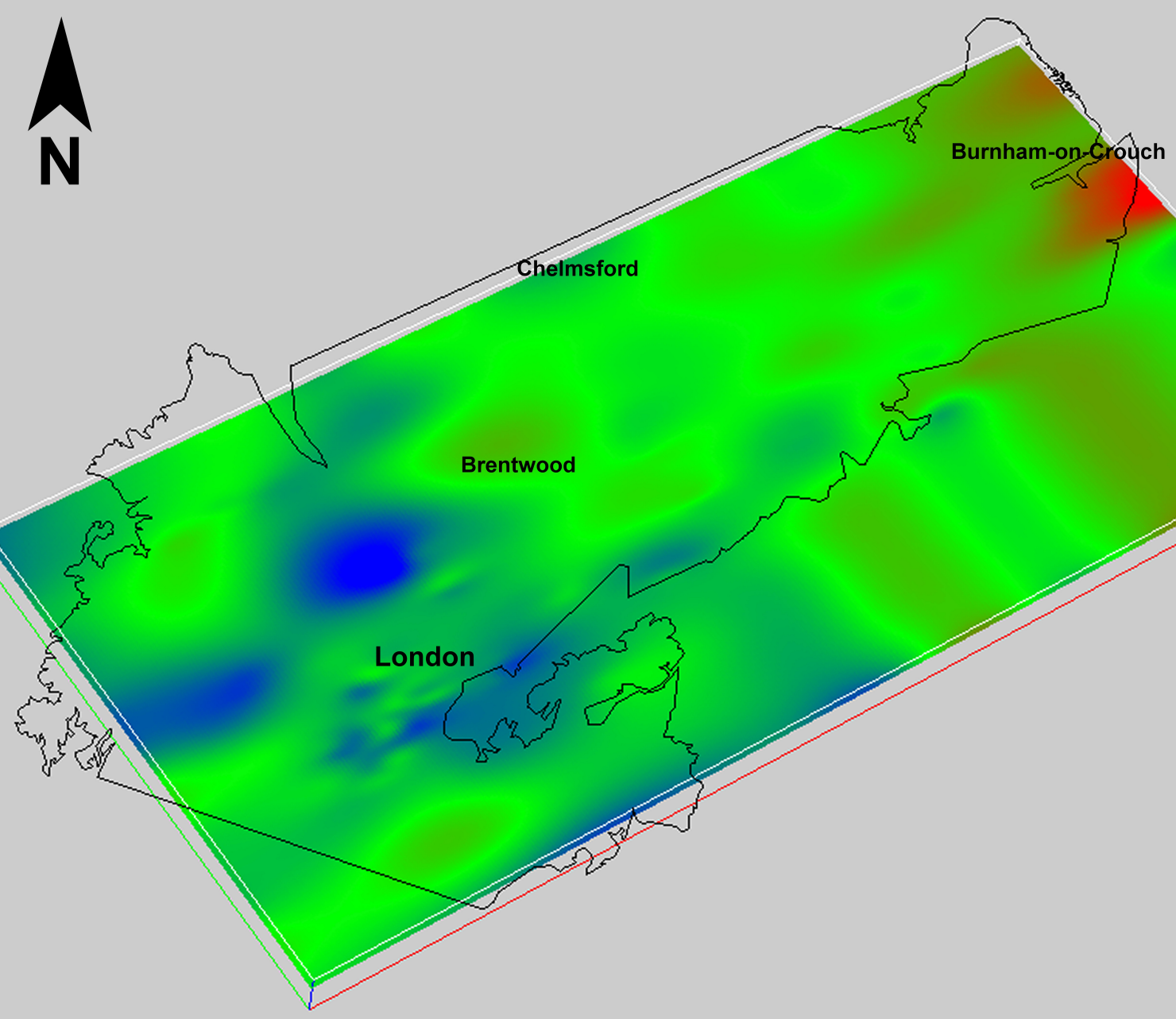




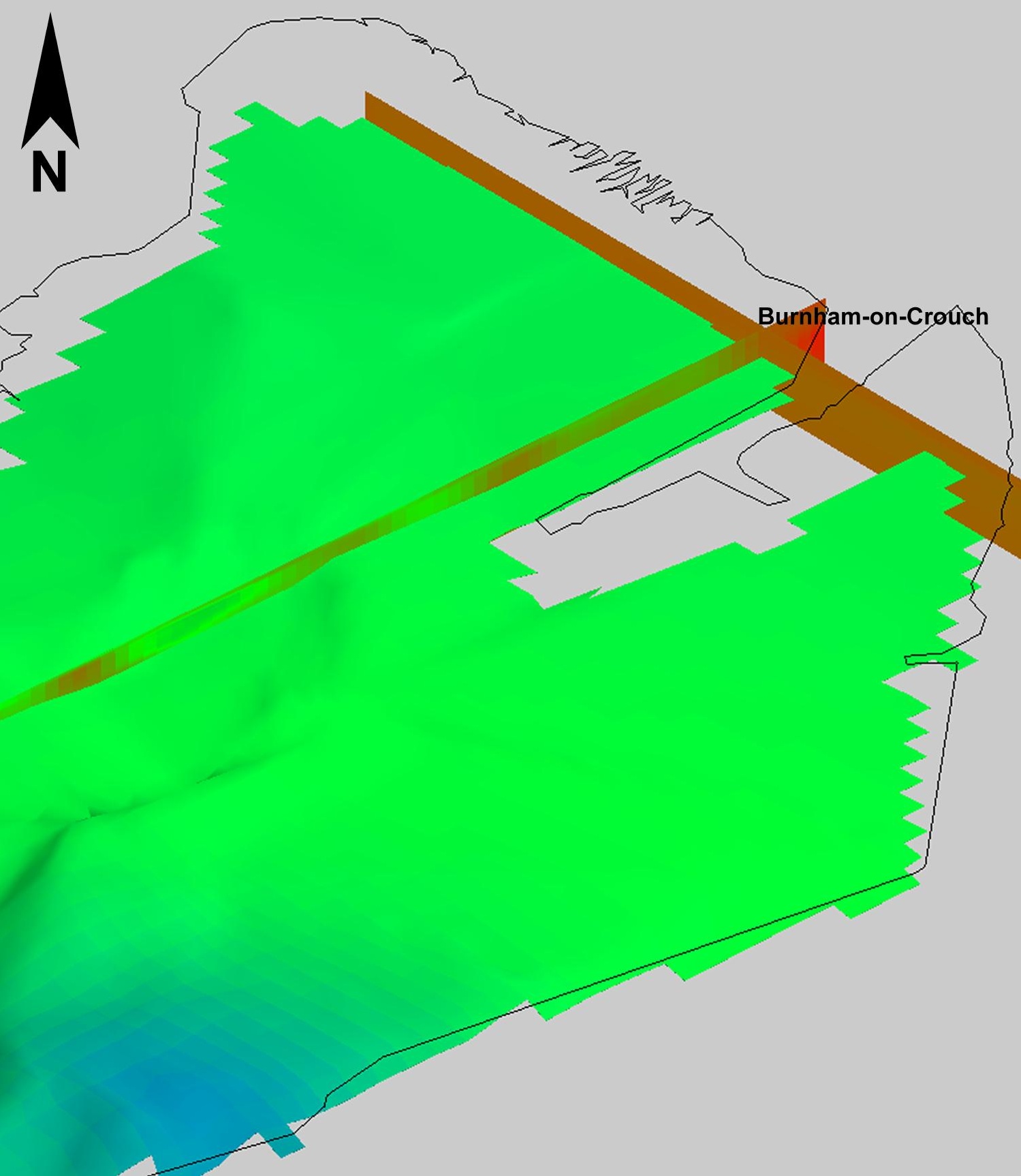


a) $0 \mathrm{~m} \mathrm{bgl}$

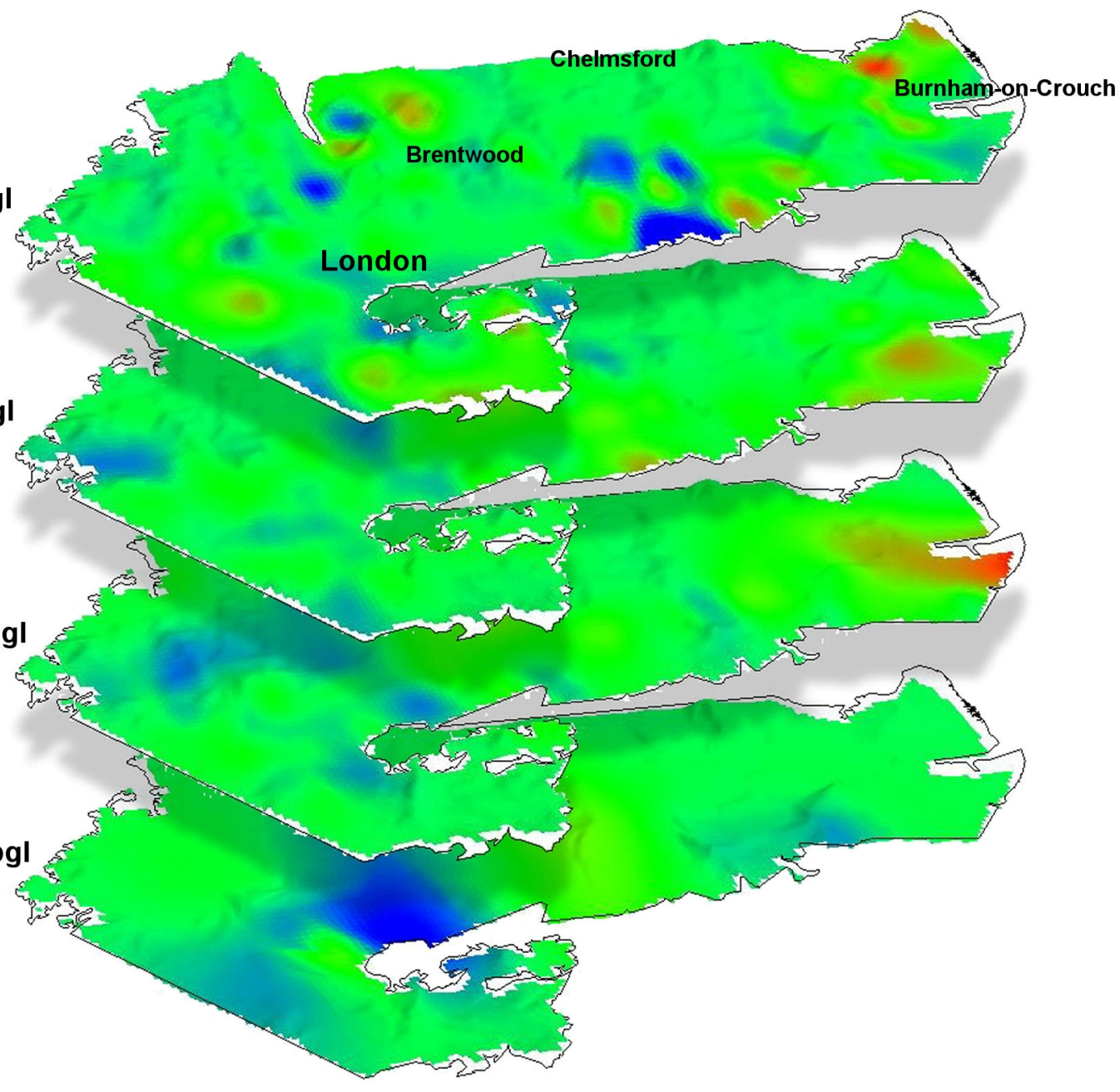

b) $8 \mathrm{~m} \mathrm{bgl}$

c) $20 \mathrm{~m} \mathrm{bgl}$

d) $50 \mathrm{~m} \mathrm{bgl}$ 